\title{
Rapid Synthesis and Characterization of an Oxygen-Deficient Defect Perovskite $\mathrm{La}_{4} \mathrm{BaCu}_{5} \mathrm{O}_{13+\delta}$ Phase
}

\author{
Chikkadasappa Shivakumara \\ Solid State and Structural Chemistry Unit, Indian Institute of Science, Bangalore 560 012, India \\ Correspondence should be addressed to Chikkadasappa Shivakumara, shikumarc@gmail.com
}

Received 10 June 2011; Accepted 18 July 2011

Academic Editors: O. Dymshits and A. Ravaglioli

Copyright ( $) 2011$ Chikkadasappa Shivakumara. This is an open access article distributed under the Creative Commons Attribution License, which permits unrestricted use, distribution, and reproduction in any medium, provided the original work is properly cited.

Oxygen-deficient defect perovskite $\mathrm{La}_{4} \mathrm{BaCu}_{5} \mathrm{O}_{13+\delta}$ phase has been synthesized by the nitrate-citrate gel combustion method at $950^{\circ} \mathrm{C}$ for $2 \mathrm{~h}$. Structural parameters were refined by the Rietveld refinement method using room-temperature powder XRD data. The $\mathrm{La}_{4} \mathrm{BaCu}_{5} \mathrm{O}_{13+\delta}$ crystallizes in the tetragonal structure with space group $P 4 / m$ (no. 83) and having the lattice parameters $a=8.6508(1) \AA$ and $c=3.8606(2) \AA$, respectively. Oxygen content was determined by the iodometric titration. Low-temperature resistivity result reveals that $\mathrm{La}_{4} \mathrm{BaCu}_{5} \mathrm{O}_{13+\delta}$ compound exhibit metallic behavior up to $15 \mathrm{~K}$.

\section{Introduction}

The oxygen-deficient defect perovskite of the formula $\mathrm{La}_{4} \mathrm{BaCu}_{5} \mathrm{O}_{13+\delta}$, first reported by Michel et al. [1] is tetragonal, space group $P 4 / m, a \approx \sqrt{5 a_{p}}=8.644 \AA, c \approx$ $a_{p}=3.867 \AA$, where $a_{p}$ refers to a perovskite sub cell. The model structure [2] consists of groups of four corner-sharing $\mathrm{CuO}_{5}$ pyramids linked through $\mathrm{CuO}_{6}$ octahedra in such a way that each octahedron shares four corners with four pyramids and two corners with two other octahedra; each pyramid are connected to four other pyramids and one octahedron. The framework exhibits one perovskite-like tunnel and two hexagonal tunnels per cell. $\mathrm{Ba}^{2+}$ and $\mathrm{La}^{3+}$ are ordered, with 12-coordinate $\mathrm{Ba}^{2+}$ in perovskite tunnels and 10-coordinate $\mathrm{La}^{3+}$ in hexagonal tunnels $[2,3]$. $\mathrm{La}_{4} \mathrm{BaCu}_{5} \mathrm{O}_{13+\delta}$ is unique, because it shows metallic behavior down to lowest possible temperature without undergoing superconducting transition. Mamiya et al. [4] measured the electrical resistivity of $\mathrm{La}_{4} \mathrm{BaCu}_{5} \mathrm{O}_{13}$ compound down to $39 \mathrm{mK}$ without observing superconductivity, because of a three-dimensional network of $\mathrm{CuO}_{5}$ units. Substitution for the La-site by other rare earth ions in $\mathrm{La}_{4} \mathrm{BaCu}_{5} \mathrm{O}_{13+\delta}$ system has been performed by Vijayaraghavan et al. [5]. Oxygen stoichiometry in $\mathrm{La}_{4} \mathrm{BaCu}_{5} \mathrm{O}_{13+\delta}$ can be varied to induce a metal-insulator transition [6]. Defect perovskite phases with $\delta=-0.5$ and -1.0 have been identified by Davies and Katzan [3] and also by Kato et al. [7]. We have synthesized $\mathrm{La}_{4} \mathrm{BaCu}_{5-x} \mathrm{M}_{x} \mathrm{O}_{13+\delta}(\mathrm{M}=\mathrm{Ni}, \mathrm{Co}, 0.0 \leq \mathrm{X} \leq 1.0 ; \mathrm{Fe}$, $\mathrm{X} \leq 0.5)$ by low-temperature $\mathrm{NaOH}-\mathrm{KOH}$ flux methods $[8,9]$. Further, we have shown [10] an anisotropic electrical transport property in $\mathrm{La}_{4} \mathrm{BaCu}_{5} \mathrm{O}_{13.14}$ and $\mathrm{La}_{4} \mathrm{BaCu}_{4} \mathrm{NiO}_{13.20}$ epitaxial thin films: in the $a-b$ plane, it is semiconducting, while along the $c$-direction, it is metallic. Anderson et al. [11] prepared $\mathrm{La}_{4} \mathrm{BaCu}_{5} \mathrm{O}_{13+\delta}$ and $\mathrm{La}_{4} \mathrm{BaCu}_{5-x} \mathrm{M}_{x} \mathrm{O}_{13+\delta}(\mathrm{M}=\mathrm{Ni}$, $\mathrm{Co}, \mathrm{Fe}, \mathrm{Zn}$ ) by conventional solid state method at $1000^{\circ} \mathrm{C}$ for $48 \mathrm{~h}$.

However, a wet chemical route such as nitrate-citrate gel combustion route can be excellent method for the synthesis of pure multicomponent oxides. Potential advantages of wet chemical route over the conventional solid state reaction method include better homogeneity, better compositional control, and lower processing temperatures [12]. In the present study, nitrate-citrate gel combustion method was employed to prepare oxygen deficient defect perovskite $\mathrm{La}_{4} \mathrm{BaCu}_{5} \mathrm{O}_{13.20}$ phase and report the structure and electrical properties.

\section{Experimental}

Stoichiometric amounts of high-purity precalcined $\mathrm{La}_{2} \mathrm{O}_{3}$ (at $800^{\circ} \mathrm{C}$ ), $\mathrm{Ba}\left(\mathrm{NO}_{3}\right)_{2}$, and $\mathrm{CuO}$ were dissolved in $10 \mathrm{~mL}$ 


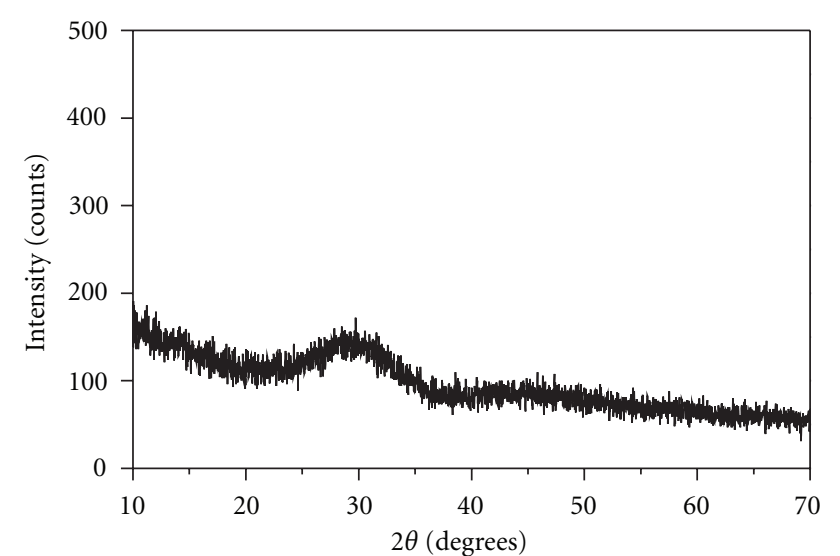

(a)

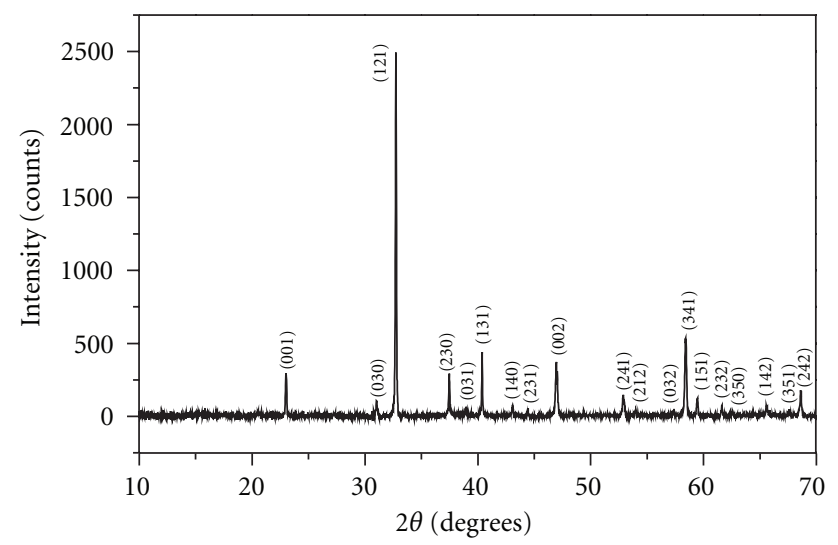

(b)

Figure 1: Powder X-ray diffraction patterns of $\mathrm{La}_{4} \mathrm{BaCu}_{5} \mathrm{O}_{13.20}$ compound (a) as prepared (before calcination) and (b) calcined at $950^{\circ} \mathrm{C}$ for $2 \mathrm{~h}$.

of $\mathrm{HNO}_{3}(8 \mathrm{~N})$ and the required amount of citric acid solution was added. The resulting clear solution was slowly evaporated on a hot plate to dryness followed by calcined at elevated temperature to yield final product. A typical run included the following steps: $\mathrm{La}_{2} \mathrm{O}_{3}(1.3033 \mathrm{~g}), \mathrm{Ba}\left(\mathrm{NO}_{3}\right)_{2}$ $(0.5227 \mathrm{~g})$, and $\mathrm{CuO}(0.7955 \mathrm{~g})$ were dissolved in $10 \mathrm{~mL}$ of $\mathrm{HNO}_{3}(8 \mathrm{~N})$, citric acid $(6.1478 \mathrm{~g})$ was dissolved in $100 \mathrm{~mL}$ of distilled water and added to the metal ions-containing nitrate solution. The clear green color solution was evaporated on hot plate $\sim 80^{\circ} \mathrm{C}$, to form a thick viscous gel. The resulting gel was heated until it turned into a black porous mass, which on continued heating on hot plate, slowly burned to yield black powder. The resulting powder was X-ray amorphous in nature. To obtain crystallinity, black powder was calcined at $950^{\circ} \mathrm{C}$ for $2 \mathrm{~h}$. The calcined sample was characterized by powder X-ray diffraction (XRD) using PANalytical X'pert pro diffractometer with $\mathrm{Cu} K \alpha(\lambda=$ $1.5418 \AA$ A) radiation equipped with X'cellerator. For Rietveld refinement, data were collected at a scan rate of $1^{\circ} / \mathrm{min}$. with a $0.02^{\circ}$ step size for $2 \theta$ from $10^{\circ}$ to $100^{\circ}$. The data were refined using the FullProf Suite-2000 version. Morphology and compositional analysis were carried out in a scanning electron microscope (SEM) fitted with an energy dispersive

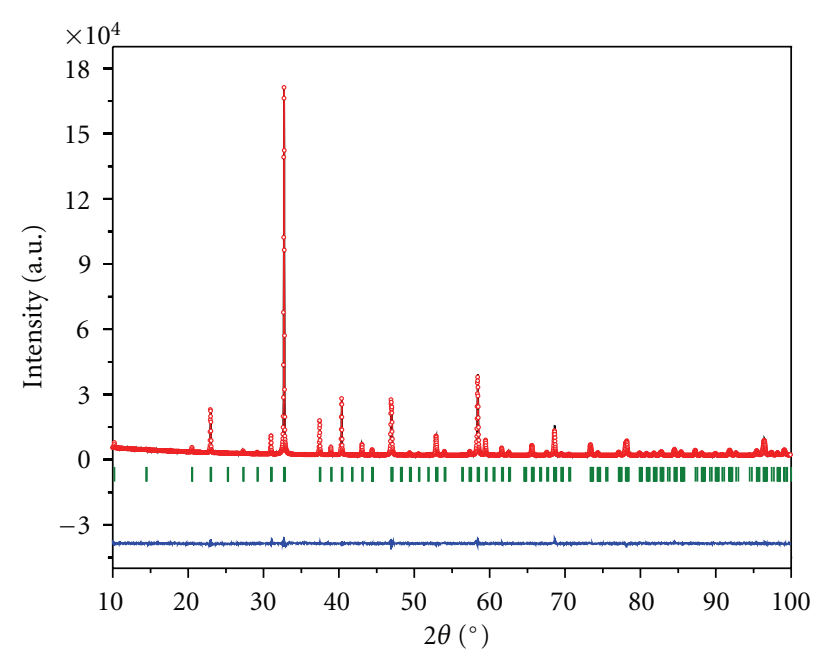

La4.PRF:

- Yobs

- Ycalc

- Yobs-Ycalc

FIGURE 2: Observed, calculated and the difference Rietveld refined $\mathrm{X}$-ray diffraction patterns of $\mathrm{La}_{4} \mathrm{BaCu}_{5} \mathrm{O}_{13.20}$ compound sintered at $850^{\circ} \mathrm{C}$ for $12 \mathrm{~h}$.



FIgure 3: Crystal structure of $\mathrm{La}_{4} \mathrm{BaCu}_{5} \mathrm{O}_{13.20}$ compound.

$\mathrm{X}$-ray analyzer (EDX). Electrical resistivity measurement was carried out on sintered pellets $\left(850^{\circ} \mathrm{C}, 12 \mathrm{~h}\right)$ by a four-probe method in the temperature range from 300 to $15 \mathrm{~K}$.

2.1. Determination of Oxygen Content. Oxygen content was determined by iodometric titration [8]. Typically, about $50 \mathrm{mg}$ of the compound was dissolved in $10 \mathrm{~mL}$ of $\mathrm{HCl}(6 \mathrm{~N})$ containing about $1 \mathrm{~g}$ of solid KI. Liberated iodine was titrated 
TABLE 1: Rietveld refined structural parameters for $\mathrm{La}_{4} \mathrm{BaCu}_{5} \mathrm{O}_{13.20}$ compound.

\begin{tabular}{|c|c|c|c|c|c|c|}
\hline Atoms & Oxidation state & Wyckoff notations & $x$ & $y$ & $z$ & Occupancy \\
\hline La1 & 3 & $(4 \mathrm{k})$ & $0.1280(2)$ & $0.2780(2)$ & 0.5000 & 1 \\
\hline $\mathrm{Ba} 1$ & 2 & (1d) & 0.5000 & 0.5000 & 0.5000 & 1 \\
\hline $\mathrm{Cul}$ & 2.44 & (1a) & 0.0000 & 0.0000 & 0.0000 & 1 \\
\hline $\mathrm{Cu} 2$ & 2.44 & $(4 \mathrm{j})$ & $0.4165(5)$ & $0.1719(4)$ & 0.0000 & 1 \\
\hline O1 & -2 & (1b) & 0.0000 & 0.0000 & 0.5000 & 1 \\
\hline $\mathrm{O} 2$ & -2 & $(2 \mathrm{e})$ & 0.0000 & 0.5000 & 0.0000 & 0.10 \\
\hline $\mathrm{O} 3$ & -2 & $(4 \mathrm{j})$ & $0.2822(2)$ & $0.3936(6)$ & 0.0000 & 1 \\
\hline $\mathrm{O} 4$ & -2 & $(4 \mathrm{j})$ & $0.2244(3)$ & $0.0551(5)$ & 0.0000 & 1 \\
\hline O5 & -2 & $(4 \mathrm{k})$ & $0.4119(8)$ & $0.1501(9)$ & 0.5000 & 1 \\
\hline
\end{tabular}

Crystal system = tetragonal, lattice parameters, $a=8.6508(1), c=3.8606(2)$; space group $=P 4 / m($ no. 83$) ; R$ factors, $R_{\mathrm{p}}=3.72, R_{\mathrm{wp}}=5.27, R_{\mathrm{Bragg}}=5.12$, $R_{\mathrm{F}}=4.97$.

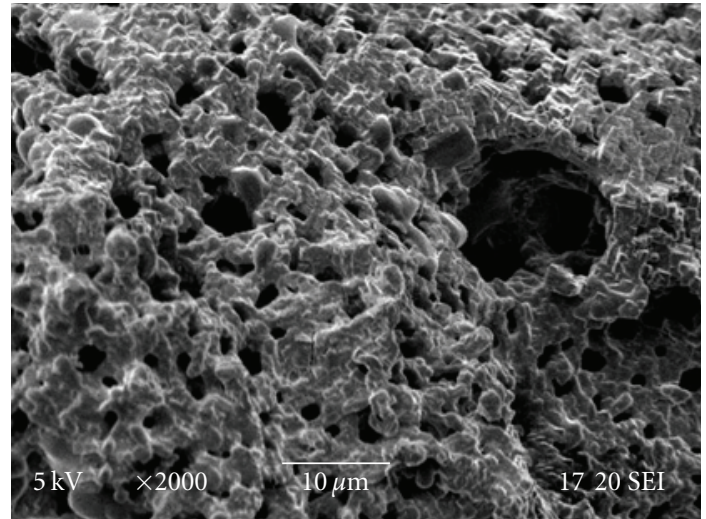

(a)

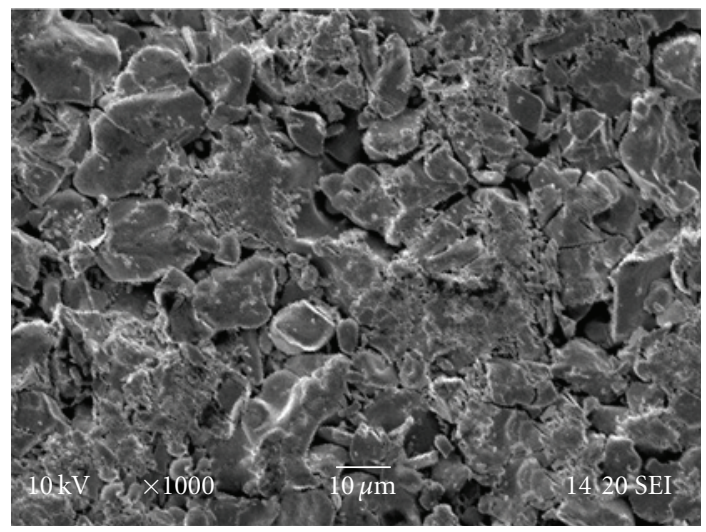

(b)

FIGURE 4: Scanning electron micrographs of $\mathrm{La}_{4} \mathrm{BaCu}_{5} \mathrm{O}_{13.20}$ compound (a) calcined powder for $2 \mathrm{~h}$ and (b) pellet sintered at $850^{\circ} \mathrm{C}$ for $12 \mathrm{~h}$.

against standard sodium thiosulphate $(0.05 \mathrm{~N})$ solution using starch as an indicator.

\section{Results and Discussion}

Figure 1, shows the typical powder X-ray diffraction patterns for (a) as formed and (b) calcined at $950^{\circ} \mathrm{C}$ for $2 \mathrm{~h}$. As can be seen from the Figure 1(a), as formed compound is an amorphous in nature. All metal ions are homogeneous in the mixture and are an amorphous in nature. To obtain crystalline phase calcinations was done at different temperature from $600^{\circ} \mathrm{C}$ to $1000^{\circ} \mathrm{C}$ for a period of $2 \mathrm{~h}$. The single crystalline oxygen-deficient defect perovskite, $\mathrm{La}_{4} \mathrm{BaCu}_{5} \mathrm{O}_{13+\delta}$ phase was obtained at $950^{\circ} \mathrm{C}$ for $2 \mathrm{~h}$. Indexed powder X-ray diffraction pattern for $\mathrm{La}_{4} \mathrm{BaCu}_{5} \mathrm{O}_{13+\delta}$ compound is given in Figure 1(b). Oxygen content was determined by iodometric titration for the calcined sample, the wet chemical analysis results reveal that the average oxidation state of copper was found to be +2.48 . The final formula of the compound was $\mathrm{La}_{4} \mathrm{BaCu}_{5} \mathrm{O}_{13.20}$. The structure of the $\mathrm{La}_{4} \mathrm{BaCu}_{5} \mathrm{O}_{13.20}$ compound was refined by powder X-ray Rietveld analysis. The compound crystallizes in the tetragonal structure with space group $P 4 / m$ (no. 83) and having the lattice parameters $a=8.6508(1) \AA$ and $c=3.8606(2) \AA$, respectively. Observed, calculated, and the difference X-ray diffraction patterns for $\mathrm{La}_{4} \mathrm{BaCu}_{5} \mathrm{O}_{13.20}$ compound is given in Figure 2, and there is good agreement between observed and calculated pattern. Rietveld refined structural parameters are summarized in Table 1. The refined structural parameters are agreed well with those reported in the literature $[2,8]$. Crystal structure of $\mathrm{La}_{4} \mathrm{BaCu}_{5} \mathrm{O}_{13.20}$ compound was shown in Figure 3. The structure consists of groups of four corner-sharing $\mathrm{CuO}_{5}$ pyramids linked through $\mathrm{CuO}_{6}$ octahedra. Each octahedron shares four corners with four pyramids and two corners with two other octahedra; each pyramid is connected to four other pyramids and one octahedron. The framework exhibits one perovskite-like tunnel and two hexagonal tunnels per cell. $\mathrm{Ba}^{2+}$ and $\mathrm{La}^{3+}$ are ordered, with 12-coordinate $\mathrm{Ba}^{2+}$ in perovskite tunnels and 10 -coordinate $\mathrm{La}^{3+}$ in hexagonal tunnels.

The surface morphology and grain sizes of $\mathrm{La}_{4} \mathrm{BaCu}_{5} \mathrm{O}_{13.20}$ compound have been investigated by scanning electron microscopy. In Figure 4, shown the micrographs of $\mathrm{La}_{4} \mathrm{BaCu}_{5} \mathrm{O}_{13.20}$ phase (a) calcined powder for $2 \mathrm{~h}$ and (b) pellet sintered at $850^{\circ} \mathrm{C}$ for $12 \mathrm{~h}$. From Figure 4(a), the powder sample shows voluminous and porous morphology. The porous nature of combustion derived calcined powder can be attributed to large amount of gases 


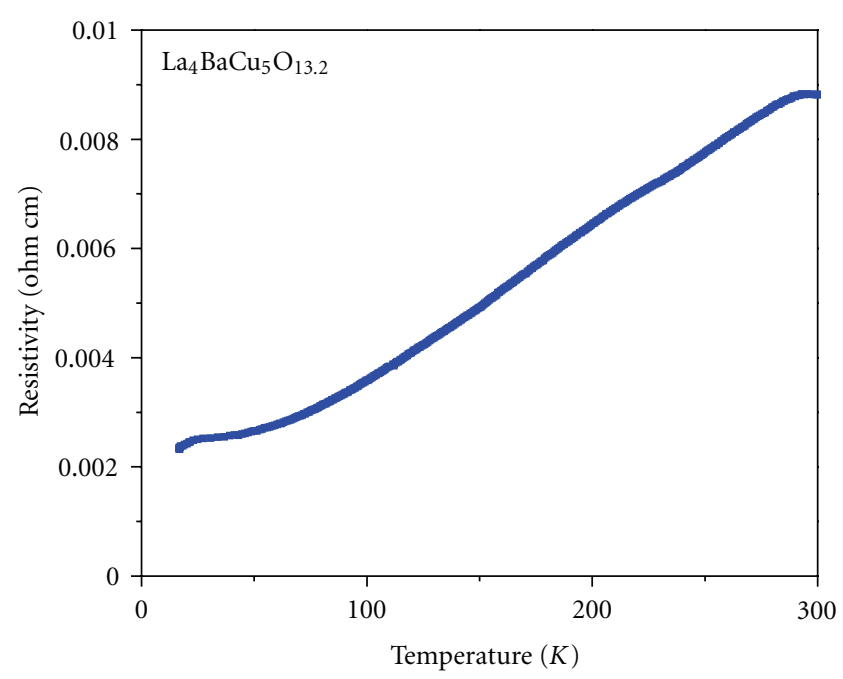

FIgURe 5: Plot of electrical resistivity as a function of temperature for $\mathrm{La}_{4} \mathrm{BaCu}_{5} \mathrm{O}_{13.20}$ compound.

evolved during combustion reaction. On the other hand sintered pellet at $850^{\circ} \mathrm{C}$ shows growth in particle sizes and well-defined grain boundary (see Figure 4(b). The agglomerated particles sizes are in the range of $10-20 \mu \mathrm{m}$, the micrograph indicate that the sintered pellet shows densification and compactability compared to the calcined powder. Compositional analysis was verified by the energy dispersive X-ray analysis (EDX). The measurements were done on the spot mode and overall area of the sample, and EDX analysis on several spots revealed constancy of compositions.

Four-probe electrical resistivity as a function of temperature measurement was performed on the pellet sintered at $850^{\circ} \mathrm{C}$ for $12 \mathrm{~h}$. Resistivity as a function of temperature plot of $\mathrm{La}_{4} \mathrm{BaCu}_{5} \mathrm{O}_{13.20}$ compound is given in Figure 5 . The compound shows a positive temperature coefficient of resistivity, typical of a metal down to $15 \mathrm{~K}$, with the resistivity varying from $0.88 \mathrm{~m} \Omega \mathrm{cm}$ at $300 \mathrm{~K}$ to $0.23 \mathrm{~m} \Omega \mathrm{cm}$ at $15 \mathrm{~K}$. The present resistivity value is comparable with those reported in the literature [8].

\section{Conclusions}

In conclusion, oxygen-deficient defect perovskite $\mathrm{La}_{4} \mathrm{BaCu}_{5} \mathrm{O}_{13.20}$ phase is successfully synthesized by the rapid nitrate-citrate gel combustion method. Crystal structure was confirmed by the Rietveld refinement method using roomtemperature powder XRD data. The compound crystallizes in the tetragonal structure and exhibit metallic property.

\section{Acknowledgment}

The author thanks Department of Science and Technology, (DST-FIST), Government of India, New Delhi, for providing XRD facility to carry out this research work.

\section{References}

[1] C. Michel, L. Er-Rakho, and B. Raveau, "The oxygen defect perovskite $\mathrm{La}_{4} \mathrm{BaCu}_{5} \mathrm{O}_{13+\delta}$, a metallic conductor," Materials Research Bulletin, vol. 20, no. 6, pp. 667-671, 1985.

[2] C. Michel, L. Er-Rakho, M. Hervieu, J. Pannetier, and B. Raveau, " $\mathrm{La}_{4} \mathrm{BaCu}_{5} \mathrm{O}_{13+\delta}$, an oxygen-deficient perovskite built up from corner-sharing $\mathrm{CuO}_{6}$ octahedra and $\mathrm{CuO}_{5}$ pyramids," Journal of Solid State Chemistry, vol. 68, no. 1, pp. 143-152, 1987.

[3] P. K. Davies and C. M. Katzan, "Oxidation and reduction of $\mathrm{BaLa}_{4} \mathrm{Cu}_{5} \mathrm{O}_{13+\delta}$," Journal of Solid State Chemistry, vol. 88, no. 2, pp. 368-383, 1990.

[4] T. Mamiya, K. Hattori, H. Shibayama, K. Iwahashi, T. Kusakabe, and $\mathrm{K}$. Adachi, "Electrical resistivity of nonsuperconducting $\mathrm{La}_{4} \mathrm{BaCu}_{5} \mathrm{O}_{13}$ and $\mathrm{La}_{5} \mathrm{SrCu}_{6} \mathrm{O}_{15}$-based compounds down to the $\mathrm{mK}$ temperature range," Physica B, vol. 194-196, no. 2, pp. 1523-1524, 1994.

[5] R. Vijayaraghavan, R. A. Mohan Ram, and C. N. R. Rao, "A series of metallic oxides of the formula $\mathrm{La}_{3} \mathrm{LnBaCu}_{5} \mathrm{O}_{13+\delta}(\mathrm{Ln}$ = rare earth or Y)," Journal of Solid State Chemistry, vol. 78, no. 2, pp. 316-318, 1988.

[6] R. Vijayaraghavan, R. A. Mohan Ram, P. Ganguly, and C. N. R. Rao, "Compositionally controlled metal-insulator transitions in the $\mathrm{La}_{4-x} \mathrm{Ba}_{1+x} \mathrm{Cu}_{5} \mathrm{O}_{13+\delta}$ system," Materials Research Bulletin, vol. 23, no. 5, pp. 719-723, 1998.

[7] M. Kato, N. Kojima, K. Yoshimura et al., "Structural phase transition of $\mathrm{La}_{4} \mathrm{BaCu}_{5} \mathrm{O}_{y}$," Journal of Solid State Chemistry, vol. 103, no. 1, pp. 253-262, 1993.

[8] C. Shivakumara, M. S. Hegde, K. Sooryanarayana, T. N. Guru Row, and G. N. Subbanna, "Low temperature synthesis, structure and properties of $\mathrm{La}_{4} \mathrm{Ba} \mathrm{Cu}_{5-x} \mathrm{M}_{x} \mathrm{O}_{13+\delta}(\mathrm{M}=\mathrm{Ni}$, Co and Fe)," Journal of Materials Chemistry, vol. 8, no. 12, pp. 2695-2700, 1998.

[9] C. Shivakumara, M. S. Hegde, H. Rajagopal, and A. Sequiera, "Neutron diffraction studies of $\mathrm{La}_{4} \mathrm{BaCu}_{4} \mathrm{MO}_{13+\delta}(\mathrm{M}=\mathrm{Ni}$ and Co) oxides," Materials Research Bulletin, vol. 35, no. 12, pp. 2063-2068, 2000.

[10] A. Venimadhav, P. Subramanya Herle, M. Vedawyas, C. Shivakumara, and M. S. Hegde, "Anisotropic electrical transport property in $\mathrm{La}_{4} \mathrm{BaCu}_{5} \mathrm{O}_{13+\delta}$ and $\mathrm{La}_{4} \mathrm{BaCu}_{4} \mathrm{NiO}_{13+\delta}$ epitaxial thin films," Applied Physics Letters, vol. 75, no. 11, pp. 15981600, 1999.

[11] P. S. Anderson, C. A. Kirk, J. M. S. Skakle, and A. R. West, "Synthesis and characterization of $\mathrm{La}_{4} \mathrm{BaCu}_{5} \mathrm{O}_{13+\delta}$ and $\mathrm{La}_{4} \mathrm{BaCu}_{5-x} M_{x} \mathrm{O}_{13+\delta}: \mathrm{M}=\mathrm{Fe}, \mathrm{Co}, \mathrm{Ni}, \mathrm{Zn}$," Journal of Solid State Chemistry, vol. 170, no. 1, pp. 1-8, 2003.

[12] M. Kakihana, "'Sol-Gel" preparation of high temperature superconducting oxides," Journal of Sol-Gel Science and Technology, vol. 6, no. 1, pp. 7-55, 1996. 

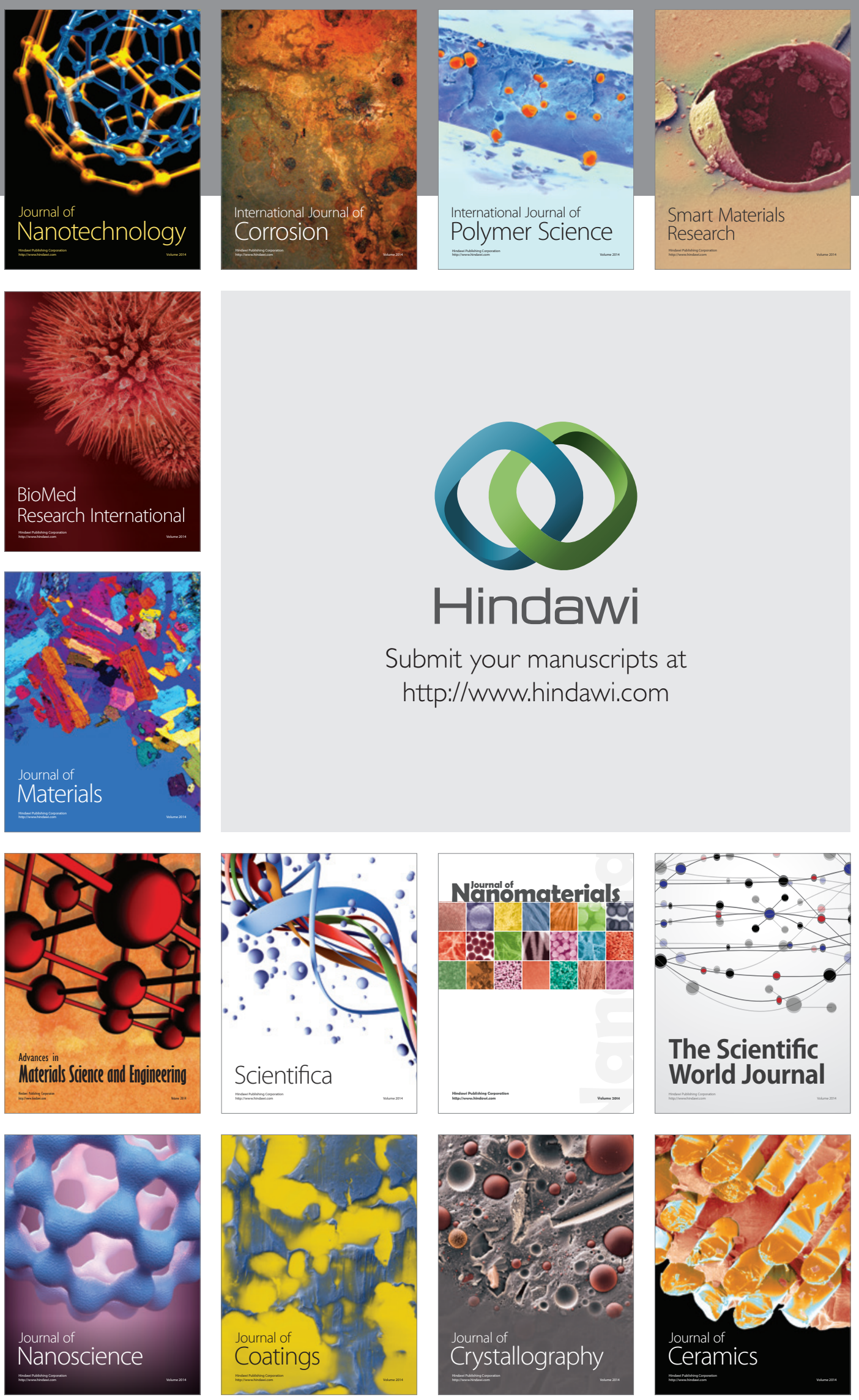

The Scientific World Journal

Submit your manuscripts at

http://www.hindawi.com

\section{World Journal}

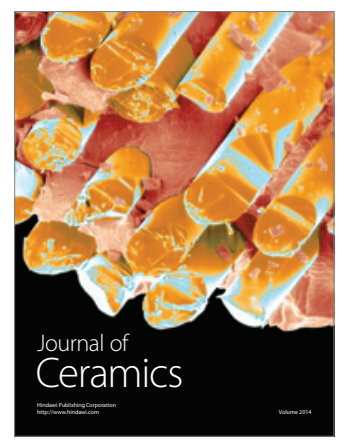

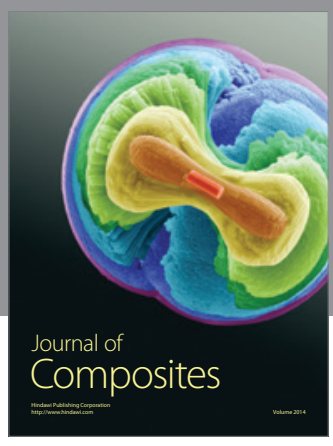
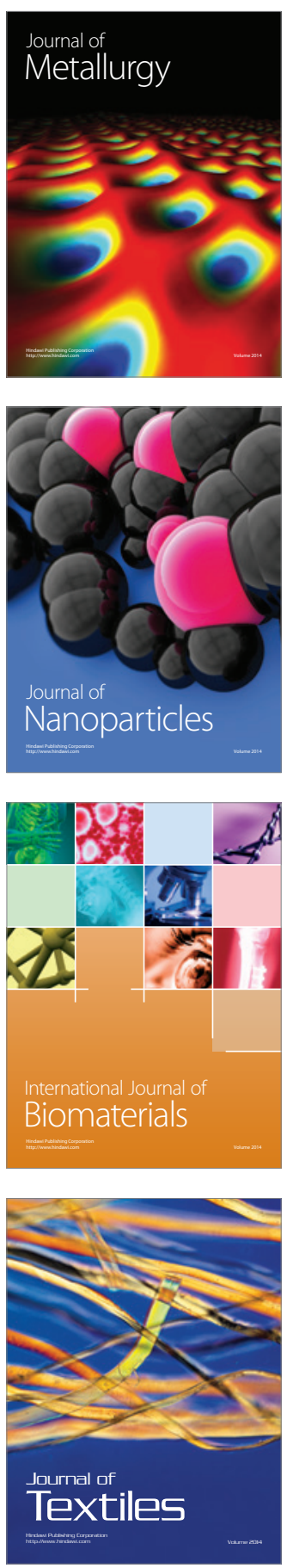